\title{
Leveraging ACBSP Collaboration to Promote Articulation for Seamless Transfer
}

\author{
Cathy M. Littlefield \\ Peirce College \\ Jane M. Mattes \\ Community College of Baltimore County
}

\begin{abstract}
Programmatic accreditation through the Accreditation Council for Business Schools and Programs (ACBSP) provides academic consistency and fosters mutual respect among members. When two ACBSP institutions enter into an articulation agreement, the students benefit from seamless, continued education from a two-year to four-year degree completion. Two such institutions, the Community College of Baltimore County, Baltimore, MD, and Peirce College, Philadelphia, PA share their experience as a way to encourage ACBSP programmatic accreditation and the collaboration of other ACBSP accredited programs.
\end{abstract}

Keywords: articulation, external partnerships, programmatic accreditation, transfer

\section{INTRODUCTION}

To promote enrollment stabilization, the Community College of Baltimore County (CCBC) created CCBC Online to increase the number of fully online programs available to students locally, in the Baltimore region, and beyond. A related goal was to build external partnerships with four-year institutions that offer comparable fully online programs and to develop articulation agreements that would provide CCBC graduates with quality transfer options.

\section{ACBSP PROGRAMMATIC ACCREDITATION EXPEDITES GOAL ACHIEVEMENT}

At $\mathrm{CCBC}$, we recognized a unique opportunity to meet our goal by pursuing articulation agreements with four-year ACBSP accredited institutions with comparable fully online bachelor's degree programs. Given the ACBSP mission is to promote continuous improvement and recognize excellence in the accreditation of business programs around the world, we were confident that the quality of these comparable programs was exceptional. ACBSP programmatic accreditation helped to facilitate the development of this articulation agreement between CCBC and Peirce College, to maximize the number of courses accepted in transfer, and to mitigate any concerns about the quality and rigor of courses.

As a first step, Jane contacted ACBSP representatives to ask if they track fully online programs by institution. While that metric is not formally captured within the ACBSP database, she was able to obtain a list of potential four-year candidates to pursue. By conducting Internet searches and contacting 
institutional representatives, Jane was able to build the external partnerships coupled with the formal articulation agreements. Contacts made through ACBSP regional and annual conferences helped to facilitate discussions with external partners and to ultimately finalize the articulation agreements.

\section{Strategic Benefits of Articulation Agreement Between CCBC and Peirce College}

Specifically, the articulation agreement between CCBC and Peirce College is an excellent example of these efforts. As an added bonus from the discussions that ensued, it was realized that opportunities existed to create articulation maps for four additional complementary programs that are not accredited by the ACBSP. Both CCBC and Peirce College have dedicated, experienced articulation staff who facilitated this process in conjunction with academic departments.

As an institution with a 154-year history as a business school, currently offering undergraduate and graduate degrees, Peirce College was a logical pairing for an articulation agreement between a community college and a four-year college. Likewise, CCBC has a similar curricular offering with more than 60 online degree and certificate options, including fully online programs in accounting and business administration. The alignment between CCBC and Peirce College was strategic, in that both offer robust and established online learning, plus both have strong business programs accredited by ACBSP. Additionally, the missions of the two institutions are similar, speaking to personalized education, transforming lives, achieving goals, and fulfilling workforce needs.

Historically, the most successful students at Peirce College are those who follow the pathway of an associate degree from a community college. In fact, Peirce data shows $71 \%$ of the students who enroll within one year of earning an AS from a community college go on to earn a bachelor's degree. Furthermore, $57 \%$ who enroll more than one year after earning an AS from a community college earn their bachelor's; and when that same student works for one of Peirce's many corporate partners, the rate increases to $87 \%$ who earn their bachelor's degree. Students who enroll with transfer credit have a proven track record for success at Peirce, which further distinguished the articulation agreement with CCBC was a natural fit.

When an articulation agreement between ACBSP institutions is in place, communications occur from both sides. The two-year institution's primary role is informing students of options while creating awareness among students, faculty, and advisors. On the four-year institution side, the admissions team works to facilitate and apply optimal credit transfer for smooth transition in compliance with the agreement. Upon matriculation, the four-year institution engages in targeted communication, articulation scholarships, needs assessments, and gap analysis. As a result of institutional size, Peirce has the ability to monitor student progress closely and provide personal guidance as needed.

Given an increasing emphasis on articulation agreements at $\mathrm{CCBC}$, more resources are being identified to support this function and to aggressively promote these agreements to students. Additional resources include staffing and technology solutions to increase the visibility of articulation agreements in the CCBC college catalog and on the college's website. Faculty and academic advisors will benefit from having this information at their fingertips, and they can provide more informed recommendations to students about transfer options. In addition, with the advent of the Baltimore County and State of Maryland College Promise programs, we anticipate that more students will transfer and take advantage of articulation agreements. Peirce's perspective of an articulation partnership (more than just an agreement) is viewed as a pipeline of well performing students who become productive in the workplace and community.

\section{Next Steps in the Spirit of Continuous Improvement}

The process of developing articulation agreements has recently been further augmented by the implementation of ACBSP unified accreditation standards for associate and bachelor degrees. With beneficial articulation agreements in place, students can complete the first two years of a bachelor's degree, reduce their debt burden substantially, and be confident that their courses will transfer seamlessly

to a four-year institution. In the spirit of continuous improvement, we respectfully recommend that the ACBSP include a metric in its database to track which accredited programs are fully online by institution. 
Having this information readily available will streamline the process of developing additional articulation agreements between two-year and four-year ACBSP accredited institutions. In addition, this step could be used as a marketing tool by the ACBSP to encourage other two-year and four-year qualifying institutions to consider ACBSP programmatic accreditation. 